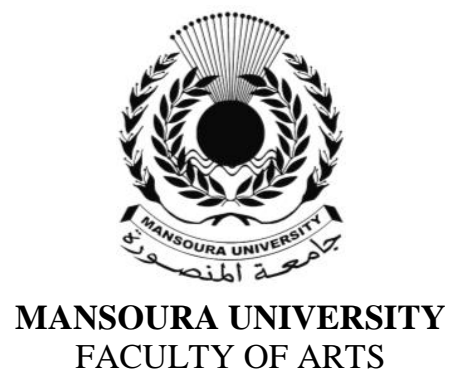

\title{
The Significance of Code- Switching in Bilingual and Multilingual Contexts
}

A research Paper in Linguistics

\author{
BY \\ Dr.Huda K.El-qassaby \\ Lecturer of English linguistics \\ The Higher institute of languages, Mansura
}

Journal Of The Faculty Of Arts- Mansoura University

$50^{\text {th }}$ ISSUE- Jan.2012 


\title{
THE SIGNIFICANCE OF CODE-SWITCHING IN BILINGUAL AND MULTILINGUAL CONTEXTS
}

\section{A RESEARCH PAPER IN LINGUISTICS}

\author{
Dr. Huda K. El-qassaby
}

\begin{abstract}
Code-switching is generally defined as a strategy used by bi-or multilingual speakers in a variety of social or learning contexts to achieve a certain desired effect.

The paper investigates code-switching as a widely manipulated phenomenon. Code-switching occurs in various contexts: Discourse, conversation, work place, as well as in educational settings. In each of these contexts, code-switching has its structure and function, depending on the participants, topics and objectives of the speakers. The paper highlights code-switching in a variety of contexts, particularly in classroom settings and the impact of this process on learning English as a FL and its significance for learners and teachers.
\end{abstract}

\section{Background}

Code-switching is known as the practice of different or variation of languages in different contexts, conversations, interactions, etc. Bilingual or multilingual speakers have the ability to code-switch or mix languages in communication. This process occurs when the bilingual or multilingual replaces a word or phrase from one language with a word or phrase from another language. It happens also when the speaker mixes two languages or uses different varieties within one language.

Code-switching is considered a pattern of appropriateness which either dictates or affects the choice of one or other language to serve a particular purpose in a particular context. For instance, English has become polarized to cover different ranges of experiences. For example, English is used as the language of literacy and formal education, whereas another language is used for commercial transaction and a third is used for entertainment. (Neil Mercer and Joan Swann, 1996:52). 
Code-switching is not a clear-cut phenomenon, and bilinguals are always free to choose, sometimes against the norm for special function. They can incorporate aspects of one language within the other or even change language entirely in certain contexts.

Actually, code-switching may itself form part of the repertoire of a speech community. (Poplock,1980:614). In this sense, a single speech act can function to express "the multiplicity of identities of the speaker".( Kamwangamalu ,1992: 45), or as (Heller,1992, pp. 34-5) has called it "double affiliation".

Recently, developments in the field of psycholinguistics emphasized how code-switching is a natural phenomenon of the bilinguals interaction. But according to the traditional view, codeswitching is looked upon as a strategy used to compensate a lack of proficiency in language use. It means that the bilingual code-switches because he or she does not master the two languages fully. This notion is known as semi-lingualism. (Heredia and Roberto R, 1997).

Generally speaking, code-switching is manipulated by bilinguals in different contexts for different reasons. It is influenced by a variety of factors such as language use (how often the first language is used) and word frequency, and so on. Finally, bilinguals code-switch for several reasons, basically for a better comprehension on the part of the speaker/listener relationship and to enhance communication as a plausible alternative.

\section{Code-switching in practice}

According to (wheeler and Rachel Swords,2008), the "correctionist approach" to language response "diagnoses the child's name speech as poor English" or "bad grammar, as the child always uses wrong plurality, possession or tense". This approach rests on the assumption that "standard English" is the only appropriate form of language. That is why classrooms tend to reject those students who are not proficient in English.

Wheeler and Swords (2001: pp. 16-6) stand for what is called "contrastivist approach" and claim that language comes in diverse varieties. This approach rests on the fact that the student's home language is not any more deficient in structure than the school language. In this sense, teachers try to guide students to know the grammatical differences between formal and informal English. Not only at the level of 
the first language use, teachers also should help students in bilingual classrooms to be aware of the grammatical differences between the SL or FL too. Having the child learned these differences, he/she will be able to switch not only between the language of home and the language of school, but also he can switch between the first language and the SL or FL, to be proper to time, audience and the purposes of communication.

In addition to the complexity of learning to use the systems of two or more languages, the bilingual child also learns how to use the language properly and how o employ all the linguistic resources in order to achieve the purpose he wants (right language for right occasion).

In some communities as well as in some bilingual families, a certain pattern of communication is used. In some families we find the child uses a certain language with the father , a different one with the mother and a third with relatives or strangers.

In some other families, the kind of language is left open according to the topic or the occasion or the desired effect. Li Wei (1994) noticed that the families' choice of a certain language can be carefully intended to achieve pragmatic effect. He quotes the following exchange between a mother and her 12-year - old son who is playing on a computer.

\section{Mother: Finished homework?}

Son: (two seconds pause)

Mother: Steven, yiu mo wan sue?

$$
\text { (want to review (your lessons?) }
$$

Son: $\quad$ (1.5 second pause) I've finished.

Li Wei (1994, p. 163)

In this short dialogue, the mother knows that communicating with her child in his preferred language (English) instead of Chinese is more effective. She is turning a question into an indirect request for the child to do his duty, This implication is easily comprehended by the child.

It is apparent that code-switching occurs among many people, from different ages and in different contexts. Sometimes, the bilinguals codeswitch when they dramatize by voice intonation and imitation of speech. In some contexts, they imitate accents, change the voice to indicate age, 
sex and personality, or distort their speech to insult a target child or group.

It is obvious from different examples in bilingual classrooms that it is not only bilinguals who are able to apply their linguistic repertoire to social situations. Also, monolingual speakers access different varieties of languages to signal shifting attitude and identities. In the following example, school boys in urban Edinburg in Scotland tend to use broader vernacular when they interact with their peers outside classrooms environment.

Kevin ... that's what we've really here (at this school) for ... to talk nice and that.

Michael ... up at X school once, playing basketball ... they started to take the micky out of all of us ... because of the way we speak . (So) you just keep your mouth shut and you don't say much.

Ian I talk with a bit of Scottish accent when I'm out in (one of the outlying towns) ... I don't really go from ... clean straight to dirty ... it's just a slight change in the way I talk ... if I talk to them with a sort of clean accent ... same accent as they do they'll just think ... you're one of us in away.

Reid, (1978, pp. 169-70)

On the other hand, the boys were careful about their speech in other people's house under the pressure posed on them by mother.

Kevin $\quad$... especially when their mother's wi them ... ken (you know) ... they just give them a wee (small) flick ... to tell them to talk nice.

When we investigate the code-switching in the work place, the following extract is recorded as a conversation in which the participants are a manager of a commercial enterprise (male) called "boss" and a (female) secretary. The two of them are Hispanic Americans whose first language is Spanish. We notice that the two speakers are fluent-bilinguals in English and Spanish. It is claimed by Fishman (1971: pp. 238-90) that they code-switch from Spanish to English to convey subtle, socialpsychological meaning. 
It is argued that the switch is accompanied by shifting from local community matters to business topics and the English of work. Consider the following example.

Boss embaryo, cuando tiened que ir a la I glesia, o la misa para pedirle

English translation (then, when they have to go church or to mass, to ask...)

Secretary (laughter)

Boss A bios entouces no var.

(god then they don't go)

Secretary Si, entouces no var

(yes, then they don't go)

Boss pero, asi es la vida, caramba.

(But this is life, you know)

Do you think that you could get this letter cut today?

Secretary Oh, yes, I'll have it this afternoon for you

Boss Ok, good, fine then.

Speakers who have a variety of dialects of English or who speak other languages, code-switch to create different characters in their conversational stories. Neil, M. and Joan, S. (1996:24).

The following example is given by( Sebba ,1993) in light of a research carried out in London. In this conversation, Andrew (A) a 15 years-old Jamaican boy speaks with Barry (B), a friend aged 16 with parents from Barbados and the southern USA. Andrew switches between London English, a London variety of Creole based on Jamaican Creole, spoken by black people born in Britain within families from India and SE with a near RE, to create different personal in his conversation with Barry. 
Transcription conventions

(.) a brief pause

Switching to Creole in italics

: lengthened consonant or vowel

$\%$ glottal stop

deep brackets indicate over lopping speech

words in brackets indicate uncertain transcription

(.) a brief pause

Switching to Creole in italics

: lengthened consonant or vowel

$\%$ glottal stop

deep brackets indicate over lopping speech

words in brackets indicate uncertain transcription

A Yeah man, I was on the till on Saturday (.) and this his black man come in (.) and you know our shop, right, they u:m give refund on Lucozade

B m:

A A black man come in an'im $b(h) u:: y$ a bottle (.) of Lucozade while'e was in the shop )an' free p-e'se got free pee (3p) off is it?

A yeah

B Small ones or big ones?

A big ones and 'e drank the bottle in fron \% of us an then ask (d) for the money back (see man) "me want me money non"

B he heh He goes (pnk) (I'm on) the till guy hhh (I jus) I jus' look round at' im I said well you can't' have it (.) I

I said I'ave to open the till (w) wait till the next customer comes (.) the man just thump' is fist down an' (screw up dis for me) s no man) the manager just comes would you leave the shop before I call the security: hh the man jus' take the bottle an'fling it at me an (J) jus' catch it at the ground.

Sebba (1993, pp. 119-250) 
Code-switching in conversation is determined by complex messages about identity and allegiance. Code-switching is used in most Arab countries, whether in classrooms, in every day situations or in social interactions as a reference to social class or prestigious position. People in Arab countries switch from Arabic to English to emphasize their social identity and the high level of their education or social status.

In the fields of business, diplomacy and formal contexts, English is used as it represents the lingua-Franca of the modern age. It is generally claimed that English which is the first language of capitalism - will enter not only the linguistic repertoire of all parts of the globe but will also form new relationships with local languages and cultures.

\section{Code-switching in educational settings}

It is obvious that the choice of English as a classrooms language has become an educational policy in most of the high-leveled educational institutions. English has become an inevitable choice as the medium for classroom education in many countries. But English is actually the basic choice in situations when it is the sole official language of a country or state. India is excluded from this condition as many people receive their education in English, although it is not their native language.

When we consider code-switching as a widely observed phenomenon, particularly in multilingual and multicultural communities, we notice that it is used in both teachers' and students' interaction and discourse. Actually, the use of code-switching in classrooms is met by disagreement on the part of some researches who claim that this policy negatively affects the two languages. On the other hand, some other educationalists believe that code-switching is favored as it improves communication and enhances understanding. In fact this debate should be clarified and investigated to raise the teachers' awareness of codeswitching use in classroom discourse, in order to either enhance its use for better instruction or eliminate it in foreign language classrooms.

It is apparent that code-switching between languages in FL classrooms has become widespread strategy. Numan and Carter simply describe this process as "a phenomenon of switching from one language to another in the same discourse ." (2001 ,p. 275). By discourse we mean the interaction that occurs between teachers and student in classroom setting. In fact, it is important to realize the difference between the 
functions of code-switching in discourse, in conversation and in other bilingual contexts. This realization helps readers to get ideas about the possible application of code-switching in educational contexts which actually differs in its purposes than in other contexts.

\section{Significance of code-switching in bilingual or multilingual context}

In previous discussion, we examined the definition of codeswitching in general term. It is generally claimed that code-switching is to choose from alternatives, which language to use in a specific situation or context to fulfill a desired effect. It is a shared process between participants in the context. Actually, in every specific context, participants understand and know in what purpose as illustrated from the examples mentioned before.

This view is asserted by (Trudgill ,2000:105) as "speakers switch to manipulate or influence or define the situation as they wish, and to convey nuances of meaning and personal intention". From this definition we know that code-switching is manipulated to express personal feelings and language is adjusted to achieve these personal desires or influences.

Code-switching is used also among certain groups of people who share the same culture and religion to create a sort of intimacy throughout choosing a specific linguistic form, to express their belonging to the same identity. This phenomenon is common in bilingual communities in which individuals who have the same ethno-cultural identity are a minority.

\section{Code-switching from formal to informal within the same Language}

Standard English is the most widely used variety in classrooms settings. However, standard English is sometimes used informally, particularly when educated speakers of SE (Standard English) are chatting casually with each other, they don't stick to SE, but rather prefer to speak informally. Consider the following exchange between two English speakers as they chat casually with each other outside the classroom: 


\section{Sam : Hi, how is every thing?}

Bill: bit fine, what do yu have in mind for today's evening?

Sam: well, nothing so far, perhaps at home.

\section{Bill : think to hang out with that funny guy.}

\section{Sam: O.K. to hell both of yu .}

There is a rather small set of frequent aspects which are nonstandard and function as "social shibboleths" ( Neil, M. and Joan, S. 2002:209). These include negative forms consider the following example.

\section{* He ain't here (verb form)}

I didn't want no one to hurt no body .(double negative)

* She seen him yesterday(verb forms e.g.)

* They was laughing ( pronouns)

* He liked the play that I had wrote. (verb form)

I want them books. (pronoun)

(Perera, 1994, pp. 86-7)

In the previous example, informal English is used to discriminate one social group from another, so this negative code-switching reflects negative aspects of the language use.

\section{Code-switching by teachers}

Generally, teachers in classrooms settings tend to code-switch either consciously or unconsciously. Whether used consciously or unconsciously, code-switching should imply a certain purpose. This process of code-switching by teachers to the mother tongue is affected by the topic and nature of discussion. In grammar classes, teachers switch to the first language to make some points clear and to enhance the learners' ability to understand the differences between the structures of the two systems. Also, this switch occurs, because some students are not sometimes aware of the structure of their native language itself. In this situation, the teacher finds himself compelled to switch to the first Language for more illustration and to better the learner's understanding 
of the topic. Besides, some teachers tend to code-switching for the function of conveying emotions or intimacy between them and other students. In this condition, code-switching occurs unconsciously, on the part of the teacher.

Moreover, code-switching in classroom settings is manipulated to assert important knowledge. Teachers code-switch to native tongue for the purpose of assertion or illustration as indicated before. Lin asserts this fact in the following quote :

The teacher was anxious that her students might not understand the point clearly; she therefore sought to ensure through comprehension, through presenting the message again in Cantonese which is the students' dominant language.

(Lin, 1988, P. 78)

On the other hand, if we understand from the previous discussion that code-switching may have some positive benefits in classroom settings, it is also necessary to refer that this strategy may entail some negative effects on classrooms instruction. Researches of bilingual codeswitching pinpoint that that code -switching has a dubious value as strategy used in classroom if we aim to improve students' competence. Jacobson argues that:
"the translation into the child's vernacular of everything that is being taught may prevent him- her from ever developing the kind of English proficiency that must be one of the objectives of sound bilingual program."

( Jacobson, 1990, P.6)

It is obvious, however, that teachers sometimes use code-switching, not merely to translate the content into the TL. Johnson and Lee (1987) claim that switches are employed by teachers for three basic reasons:

1- As a ' key statement' of topic in English.

2- For expansion, clarification or expansion .

3- Restatement in English. 
In the following example, code-switching is manipulated as a teaching technique in a variety of ways. Consider the following extract, in a secondary school lesson in Malta. The English translation is given on the right-hand column.

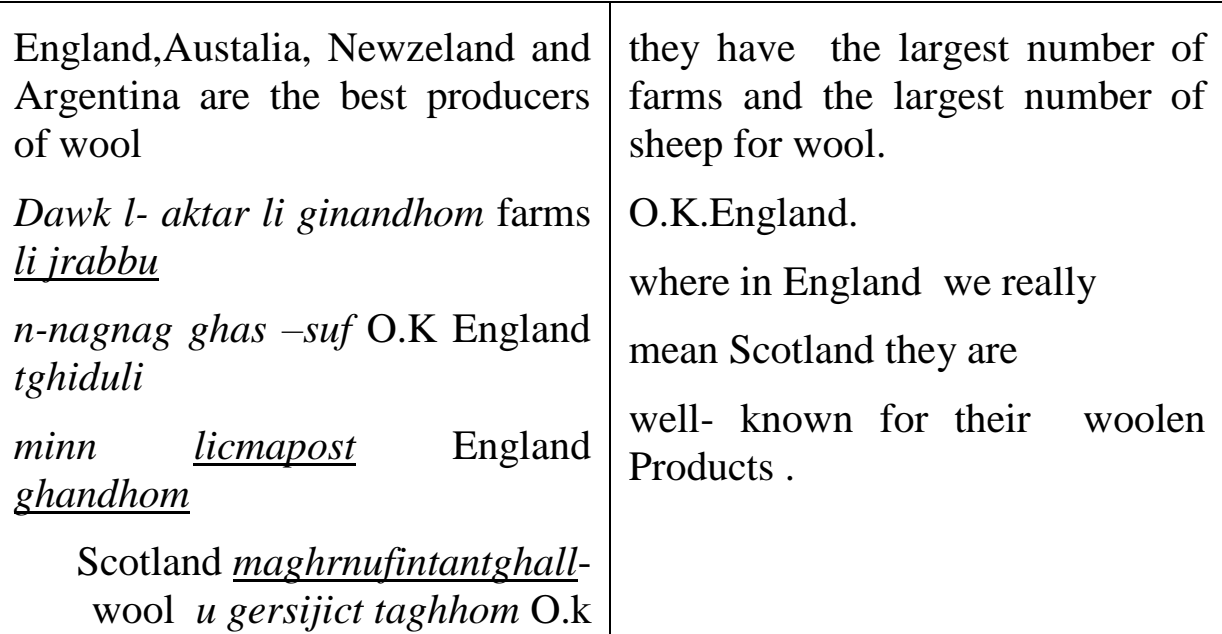

(Adopted from Camilleri,1994)

In this extract, the teacher rather switches from English to Maltese to amplify the point being made, rather than mere translating it.

In another respect, and from the researcher's long experience in the teaching of EFL, it has been noticed that some teachers code-switch to Arabic in English classes, because they are not qualified enough to teach English. Second, students themselves lose interest in studying English and sometimes they don't take it seriously, for example, a learner who knows that his teacher explains many points in Arabic becomes less enthusiastic to study the FL well, as his exposure to foreign language discourse becomes limited.

\section{Code -switching in FL classroom}

As in case of teachers' code-switching, learners of English foreign language also switch to the mother tongue, whether they are aware or not. Eldridge calls the reasons of learner's code-switching as: "equivalence floor-holding, reiteration, and conflict control". (1996: 305307). Consider the following example from English training session for Egyptian students : 
Teacher : Let me say in more simple language that grammar is the rules which govern the use of language.

\author{
Understood? Arabic (mafhum, مفهوم )
}

Student: No sir,( tany min fadlak )

Arabic ( تانى من فضلك ) again please, I don't understand.

Teacher: well, what I want to say is , Al- grammar hwa alqwaaid allaty tahkum istikdam allughah.)

$$
\text { القواعد هى التى تحكم استخدام اللغة }
$$

In the previous example, the student couldn't understand the meaning of the word (grammar), so he asked the teacher to repeat again using the mother tongue to force the teacher to explain in Arabic. Hence switching to Arabic in this context is used for more clarification.

It is claimed that using code-switching in multi-lingual classrooms in which students don't speak the same native tongue results in some problems, as some of those learners will perhaps be ignored.( Cook ,2002: 333). In this condition, code-switching shouldn't be used widely in classroom setting. This also makes the communication between students and each other more difficult.

Considering the benefits of code-switching in language instruction, it is argued that code-switching is favored in case of lack of communication or inability of expression. Also, it is required in teacher/student interaction to avoid or get rid of problems of interference. Code-switching is accepted on the part of learners to serve the purpose clarification of ambiguous meanings and to build bridges and solidarity between teachers and students as mentioned before. So, code-switching is sometimes looked upon as mixed-blessing. Accordingly, it is important to benefit from its advantages in classrooms settings and try to avoid its negative feedback as possible in language teaching. Consider the following exchange in which a student switches to Arabic English structure to express himself: 
Teacher :I want every one of you to tell me why does he want to travel abroad.

Ahmed : I want to travel to complete my study.

Teacher : so, (inta ayz tikamil drastak) انت عايز تكمل دراستك •

English :so you want to complete your study, O.K. how about Ali?

Ali : I want to secure my future.

\section{Teacher : you want what?}

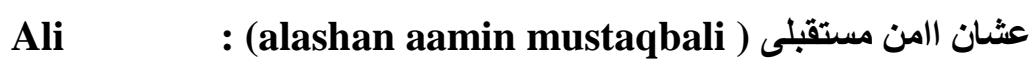

In this extract, switching to Arabic on the part of teacher is to emphasize the students' answer and to encourage other students to respond .On the part of the student, he switched to Arabic because he felt that the teacher didn't get his point, so he switched to what is called Arabic English (secure). Thus, switching to the mother tongue in English classroom setting is used for the reasons we pinpointed, such as clarification and emphasis.

Among the Egyptian learners of English, it has been noticed that big portion of students switch to Arabic. This investigation has been intended by the researcher to check the level of code-switching among the post-graduate students in speaking classes.

The researcher claims that code-switching in the FL classrooms manifests in some areas and for some reasons as shown from the following examples:

1- Students switch to Arabic when they fail to find the equivalent in English in using some connectors, such as : therefore (lizalik (عesides, in the use of the conjunction or (او (aw ) and in the use of( also) (Kaman - كمان).

2- Switching occurs, sometimes, unconsciously in the use of articles e.g., the ( al - ال )

3- Sometimes students switch to Arabic when they are not able to express themselves in Arabic and they try to illustrate what they want e.g., I mean ( yaany - يعنى).

4- Egyptian students switch to the mother tongue when they need more clarification from the tutor, as a result, they ask him to 
repeat what he said again , e.g., (mumkin tieid tany - can you repeat it again), or I don't understand (mush fahim - مش فاهم).

On the part of tutor, he switches to Arabic mainly to make sure that the students understand e.g.,. (understood- mafhum- مفهوم) or he says (again-tany- تانى).

Sometimes, when students make noise and the teacher tells them in English to keep silent, the students don't respond, accordingly, he says to them (silent- sukut- سكوت), hence then students feel that the tutor is serious, consequently they respond to him.

\section{Examples to Code-switching in a variety of contexts}

1- English-French: Je vais faire checker ma voiture

(English' to check', for verifier; is given the French infinitive marker-er to conves: I'm going to have my car checked.

2- English-Spanish: But I wanted to fight her con los punos, you know. (but I wanted to fight her with my fists, you know).

3- Swedish-English: Finn is jusy off to school: mother: Har du din nickel? (Swdis for' Hav you got your key?')

Finn: Jo; jay har der-hel hel, (yes, I've got it, goodbye:)

4- Hindi/English: maine bahut baradas kiya hai but now it's getting too much. (I have with stood a lot but..)

5- Arabic/Duch: zeibli-ya een glas water of 20 (get for me a glass of water or so)

6. Arabic/English: qamill 1-wajib (finish the homework).

\section{Conclusion}

In bilingual or multilingual societies, particularly those in which English is used alongside other languages, certain patterns of appropriateness which determine which one language are used in a specific context appear. So, English as a world language or a language of globalization is favored to cover different ranges of experiences. 
Although English has become the language of literacy, formal education and commercial transaction, English is not a clear- cut choice, but the bilingual is free to choose whatever register he finds appropriate to his or her task, even if it is against the norm of special effect .

In the company of other bilinguals, the bilingual speaker may incorporate some aspects of one language within the other, or even change language entirely.

Although the process of code-switching seems intricate in nature which requires the manipulation of more than one system, the bilingual child knows intrinsically how to switch and manipulate the available linguistic variation, whether from the family environment or from school in order to achieve the effect he finds proper for a certain purpose.

Thus, from the previous discussion alongside other studies, it is obvious that different identities and social meanings are expressed in some societies by various dialects and registers, in others by using different languages. Codes-witching is a mean of achieving hyperdized identities. Code -switching is a strategy manipulated by children as well as adults in different contexts to achieve certain goals or convey specific messages.

It is generally assumed that code-switching necessitates some factors :

1- The degree of fluency in English.

1- The bilingual competence of teachers.

2- The specific teaching goals of teachers.

3- The attitudes of both learners and teachers to the other language involved.

Throughout this paper, code-switching has been illustrated: its definition, its purposes and its negative and positive dimensions in bilingual and multilingual context. It has been pinpointed that codeswitching is widely used by children as well as by adults, to achieve a specific desired effect. A shared world between the participants in the discourse, conversation in the work place or any other social context is required to get the maximum benefit of code-switching. Also, it has been indicated that code-switching occurs from one language to another and even from one dialect or linguistic variety to another, such as shifting from formal to informal within the same language, or from colloquial to 
vernacular and so on. With regard to using code-switching in multilingual and bilingual classroom setting, it is assumed that it has its cons and pones. Some consider it a useful strategy, whereas others underestimate its benefit and value, particularly in learning foreign languages.

In all cases and regardless of its advantages, the researcher of the current paper claims that, code-switching can be an appropriate choice in any other context, but it shouldn't be relied on heavily in language classrooms, as it reduces the students interest in learning the foreign language on the part of the teacher. Teachers also should avoid codeswitching as it either reflects their inefficient skills or it reduces the students passion for learning better as this process makes them unwilling to make effort depending on their self-efficacy instead of depending on their teachers. Moreover, illustration and repeation made by instructors through code-switching to the native language must be limited to specific functions.

\section{References}

- Cammilleri, A. Talking bilingually, Writing monolingually: Paper presented at the Sociolinguistics symposium, university of Lancaster, March,1994.

- Cook, V. Portraits of the L2 user. Clevedon: Multilingual matters, 2002.

- Elderidge, J. Code-switching in a Turkish secondary school. EIT Journal, 50, 4: 303-311, 1996.

- Fishman, J. The sociology of language in Fishman, J. (ed) Advantages in sociology of language, vol. 1, the Hague, Mouton. 1971.

- Heredia, Roberto R., Bilingual memory and hierarchical models: A case for language Dominance. Current directions in psychological science 10, 1997.

- Heller, B. in Ferris, D. Treatment of Errors in SL Student Writing . Ann Arbor: University of Michigan Press, 2002.

- Jacobson R. Allocating two languages as a key features of a bilingual methodology. Clevedon, Multilingual Matters, 1990. 
- Johnson, R.K. and Lee, P.L.M. Modes of instruction: teaching strategies and student's responses in Lord, R. . and CHENG, H (eds) Language Education in Hong Kong. Hong Kong, Chinese University Press, 1987.

- Kamwangamalu, N.M Multilingual and social identity in Singapore: journal of Asian pacific communication, vol. 3. No. 1, p33.1992.

- Li Wei. Three generations, two languages, one family. Clevedon multilingual matters, 1994.

- Lin, A. Pedagogical and Para-pedagogical Levels on Interaction in the Classroom: a social interaction approach to the analysis of the code-switching behavior of a bilingual teacher in an English language lesson, Working paper in linguistics and Language Teaching, no.11, University of Hong Kong Language Center , 1988.

- Neil Mercer and Joan Swann. Learning English: development and diversity Rutledge, 2002.

- Numan, D, and carter, D. Teaching English to speakers of the languages. Cambridge: Cambridge University Press. 2001.

- Perera, K. Standard English: The debate in Brindely, S (ed.) Teaching English. London, Rutledge, 1994.

- Poplock, S. sometimes, I'll start a sentence in Spanish Y termino en espanol (sic): Linguistics, Vol. 18. Pp-581-618,1980.

- Reid, E. Social and stylistic variation in the speech of children: some evidence from Edinburgh' in Trudgill, p. (ed.) sociolinguistic patterns in British English, London, Edward Arnold, 1978.

- Sebba, M. London Jamaican: language systems in interaction, London Longman, 1993.

- Trudgill, P. Sociolinguistics. London: Penguin, 2000.

- Wheeler, Q.R. Swords, R. my gold fish name is scaly' is what we say at home. Code-switching A potent tool for reducing achievement Gap in linguistically diverse classrooms. ERIC document, 2001.

- Wheeler, R. Rachel, S. Becoming adept at code-switching "Educational leadership". 65 (7) p. 54, 2008. 